\title{
PROFESSOR EM (RE) CONSTRUÇÃO: REFLEXÕES DE UM DOCENTE EM FORMAÇÃO PEDAGÓGICA
}

\author{
D. H. KREUTZ ${ }^{1}$ e C. B. WELTER ${ }^{2}$ \\ ${ }^{1}$ dhkreutz@gmail.com, ${ }^{2}$ crisbwelter@hotmail.com \\ Universidade de Caxias do Sul
}

Artigo submetido em abril/2016 e aceito em novembro/2016

DOI: $10.15628 /$ rbept.2016.4370

\section{RESUMO}

A docência, ou seja, o ser professor na educação profissional passa pelo conhecimento da disciplina a ser ministrada e também pelo conhecimento pedagógico. Nesse sentido, o presente artigo é uma reflexão dos Estágios I e II do Programa Especial de Formação Pedagógica realizado no curso Técnico em Administração de uma escola de educação profissional nas disciplinas de Teorias e Fundamentos da
Administração e Gestão da Qualidade. A reflexão parte de um breve referencial, passando pela análise da realidade escolar e destacando práticas realizadas. Entre as práticas destacam-se o planejamento coletivo, o uso de teste de estilos de aprendizagem e uso de redes sociais. Por fim, salienta-se que a (re)construção do profissional como professor, passa pelo reconhecimento do seu papel e reflexão sobre sua atividade docente.

PALAVRAS-CHAVE: Professor; Formação Pedagógica; Educação Profissional.

\section{TEATCHER IN (RE) CONSTRUCTION: REFLEXIONS OF A DOCENT IN}

\section{PEDAGOCICAL FORMATION}

\begin{abstract}
Teaching, that is, being a teacher in professional education through the knowledge of the subject to be given and also by the pedagocical expertise. In this sense, this article is a reflection of Stages I and II of the Special Program of Pedagogical Formation carried out at the Technical Course of Management in a professional education school in the disciplines of Theories and Fundamentals of Management and Quality Management. The reflexion starts in a short reference,
\end{abstract}

going through the analysis of the school environment and highlighting activities undertaken. Among the practices are highlighted collective planning, the use of tests of learning styles and the use of social media. Lastly it is noted that the (re) construction of the professional as a teacher, passes through the recognition of their role and reflexion on their teaching activity.

KEYWORDS: Teacher; Pedagodical Formation; Professional Education. 


\title{
1 INTRODUÇÃO
}

Vivemos em um mundo de constante transformação. Novas tecnologias surgem para facilitar nossas tarefas diárias, das mais simples as mais complexas. Essas mudanças acabam por influenciar também as profissões, onde a formação inicial, muitas vezes, não é suficiente. 0 profissional em atividade deve estar em constante formação, buscando estar sempre atualizado. Uma forma interessante de conseguir isso, principalmente para graduados (bacharéis e tecnólogos) é a docência no ensino profissionalizante. Essa maneira vai de encontro a uma frase de Cora Coralina que afirma que "Feliz aquele que transfere o que sabe e aprende o que ensina" (CORALINA, 1983, p. 136). Somado a isso, o ensino profissionalizante, principalmente no que diz respeito aos cursos técnicos, ganhou grande destaque e investimentos nos últimos anos pelo governo, com destaque para o Programa Nacional de Acesso ao Ensino Técnico e Emprego PRONATEC.

Entretanto, para que essa forma de atualização possa se tornar realidade, o profissional necessita agregar conhecimentos pedagógicos a sua formação inicial. Nesse sentido, torna-se obrigatória, além da formação específica na área da docência, também uma formação pedagógica. Essa exigência está presente nas Diretrizes Curriculares Nacionais para a Educação Básica que prevê no seu artigo 40:

\begin{abstract}
A formação inicial para a docência na Educação Profissional Técnica de Nível Médio realiza-se em cursos de graduação e programas de licenciatura ou outras formas, em consonância com a legislação e com normas específicas definidas pelo Conselho Nacional de Educação. (MINISTÉRIO DA EDUCAÇÃO, 2012, texto digital).
\end{abstract}

A partir disso, o presente artigo buscou fazer uma reflexão da atividade docente do autor no curso Técnico em Administração de uma escola de educação profissional nas disciplinas de Teorias e Fundamentos de Administração e Gestão da Qualidade, ministradas entre agosto de 2014 e maio de 2015 para duas turmas distintas, onde foram realizados os estágios I e II do Programa Especial de Formação Pedagógica de Docentes.

\section{TEORIA E ANÁLISE DA REALIDADE: BASES DA REFLEXÃO}

O ser professor também foi influenciado pelos avanços tecnológicos, tanto que o ato de ensinar deixou de ser uma simples transferência, na qual o professor, dono do conhecimento, utilizava métodos tradicionais para passar o conteúdo para os alunos. Hoje, com ferramentas de busca e internet em dispositivos móveis, o aluno tem o conteúdo na palma da sua mão, não dependendo apenas do professor. Mudanças como essa destacam a importância do professor realizar uma reflexão sobre a sua atividade docente, com o objetivo de tornar as aulas atraentes, construindo o conhecimento através de pesquisas, experiências e vivências. $O$ resultado a ser alcançado com essa reflexão foi justamente uma aula de qualidade.

Para fins de contextualização, fez-se necessário a elaboração de um breve referencial teórico, construído através da revisão da literatura existente. Além disso, também se fez 
necessária conhecer a escola onde foram realizadas as práticas, sendo que essa caracterização é apresentada na análise da realidade escolar.

\subsection{Referencial teórico}

Nesse item serão apresentadas informações sobre educação profissional, planejamento docente, didática, estilos de aprendizagem e uso de novas tecnologias para aprendizagem.

\subsubsection{Educação Profissional}

Conforme o Sinpro/RS (NÍVEIS, 2008) a educação profissional é a modalidade de ensino voltada para qualificação profissional e acesso ao mercado de trabalho. Nesse sentido, abrange três diferentes cursos: formação inicial e continuada ou qualificação profissional; educação profissional técnica de nível médio; e educação profissional tecnológica de graduação e pósgraduação (BRASIL, 1996).

A educação profissional técnica de nível médio é regulamenta pelos conselhos estaduais de educação. Além disso, cada instituição de ensino profissional deve ser credenciada, bem como ter autorização para oferecer os cursos. Quanto aos cursos, eles podem ser ofertados para estudantes que estão no Ensino Médio ou que já tenham concluído o mesmo. (NÍVEIS, 2008).

Por fim, cabe destacar o PRONATEC, criado através da Lei Federal 11.513/2011 com o objetivo de: "expandir, interiorizar e democratizar a oferta de cursos de educação profissional e tecnológica no país, além de contribuir para a melhoria da qualidade do ensino médio público" (MINISTÉRIO DA EDUCAÇÃO, 2015, texto digital). Somado ao PRONATEC, também teve destaque a criação e ampliação dos Institutos Federais de Educação, Ciência e Tecnologia, sendo que ambos os projetos contribuíram para o grande crescimento da Educação Profissional nos últimos anos.

\subsubsection{Planejamento docente}

Qualquer atividade que vise lograr êxito na sua execução deve ser precedida pela etapa de planejamento. Nesse sentido, "o planejamento serve para conhecer a realidade em que se vai atuar; sugerir ações sobre essa realidade; desenvolver atividades e avaliar seus resultados permanentemente" (SENAC DN, 2009, p. 31). Com base nessa afirmação, o trabalho do docente desenvolveu-se a partir da análise da realidade apresentada no item 2.2. Gandin (2014, p. 2) acrescenta que o planejar é:

[...] buscar a transformação da realidade. É, sempre, propor ações, atitudes, regras e rotinas que possam levar à satisfação de necessidades descobertas na realidade (ou na prática) através da avaliação que é a comparação do que se quer com aquilo que existe.

Importante enfatizar a avaliação, que neste trabalho está presente na reflexão da atividade docente. A partir do exposto, percebe-se que no exercício da docência, o planejamento é uma etapa importante do processo, sendo que, de acordo com o tipo de didática predominante, muda a forma de se efetuar o planejamento. 


\subsubsection{Didática}

Inicialmente, cabe significar a palavra didática, que conforme Masetto (1997, p. 13) significa: "uma reflexão sistemática sobre o processo de ensino-aprendizagem que acontece na escola e na aula, buscando alternativas para os problemas da prática pedagógica". Essa reflexão passa pela forma como os alunos aprendem, a metodologia do professor, o relacionamento aluno-aluno bem como aluno-professor, a organização curricular, o processo de avaliação entre outros fatores que influenciam o ambiente escolar. A partir desse conceito inicial, destacam-se três correntes da didática: a tecnicista, a crítica e a pós-crítica.

A didática tecnicista, também conhecida como didática tradicional, é a corrente que defende que o professor é o detentor do conhecimento, sendo que este só é verdadeiro se for científico. $O$ processo de ensino-aprendizado está baseado na memorização, repetição e fixação, sendo que todos os alunos são considerados iguais e como uma tábula rasa, dando origem ao conceito de educação bancária. O planejamento das aulas é realizado através do plano de aula, que relata o objetivo, conteúdo, método, recursos e avaliação (MATOS, 2009).

Um passo à frente temos a didática crítica, sendo Paulo Freire um dos seus defensores no Brasil. Segundo essa didática, o conhecimento não é algo pronto a ser transmitido, mas sim algo a ser construído, sendo que o professor tem o papel de mediador, orientador. Por isso, na didática crítica o aluno ganha papel de destaque no processo de ensino-aprendizagem. 0 planejamento por sua vez é construído por projetos ou tema gerador (MATOS, 2009).

Por fim, como corrente mais moderna da didática temos a didática pós-crítica. Defendida por Nietzke, Focoult e Dluze, todos de áreas que não seja a educação. Segundo essa didática o conhecimento é produzido. Já o planejamento é feito através de temas culturais (MATOS, 2009).

\subsubsection{Estilos de aprendizagem}

Estilo de aprendizagem, conforme Mattar (2010, p. 3) "representa a maneira como cada pessoa processa, absorve e retém informações", ou seja, é a maneira pela qual uma pessoa aprende algo com maior facilidade.

Para identificação dos estilos de aprendizagem existem diferentes ferramentas entre elas o Teste Vark, proposto por Neil Fleming e Collen Mills. O questionário composto por 16 questões classifica os estilos de aprendizagem em quatro perfis: visual, aprendem melhor através de imagens, vídeos, slides, diagramas, gráficos e fluxogramas; aural, aprendem melhor ouvindo e participando de discussões; ler e escrever, aprendem melhor através de livros, dicionários, glossários e listas; e por fim o perfil cinestésico, aqueles que aprendem fazendo (MATTAR, 2010).

Matar (2010, p. 6) finaliza afirmando que "da mesma maneira que é possível falar em estilos de aprendizagem, podemos falar em estilos de 'ensinagem'. O desafio, portanto, seria adequar os estilos de ensinagem dos professores aos estilos de aprendizagem dos alunos". Nesse sentido, conhecer o estilo de aprendizagem predominante nos seus alunos permite ao professor direcionar sua atuação de maneira a facilitar o processo de ensino-aprendizagem e obter resultados positivos. 


\subsubsection{Novas tecnologias para aprendizagem}

Uma definição interessante sobre tecnologias é apresentada por Kenski (2012, p. 18): "conjunto de conhecimentos e princípios científicos que se aplicam ao planejamento, à construção e à utilização de um equipamento em um determinado tipo de atividade". Nesse sentido, inclui-se também a atividade docente, onde é de fundamental importância a utilização de novas tecnologias para tornar o processo de ensino-aprendizagem mais atraente e eficaz.

Entre algumas ferramentas que representam essas novas tecnologias para a aprendizagem, Mattar (2012) propõem: Second Life e OpenSim dentro dos mundos virtuais; Youtube e Teacher-Tube na categoria vídeos; Twitter, Blogs, Wikis, Poadcasts e Facebooks como integrantes das plataformas da web 2.0 e redes sociais; além do Skype, Slideshare, Google Docs e Prezi. Ao falar do Facebook, destaca-se que:

A página inicial do Facebook é específica para cada membro, mostrando feeds de notícias em função de suas preferências. Esse stream corre com atualizações, fotos, links e comentários de seus amigos. Mostra também atualizações de páginas que você curte ou grupos a que você pertence. É interessante lembrar a opção de se criar um perfil específico para atividades educacionais. (MATTAR, 2012, p.93)

Além disso, segundo o mesmo autor, ainda existe a possibilidade da criação de grupos e de páginas, sendo que os primeiros consistem em um lugar que pode ser aberto, privado ou fechado usado para interação, enquanto que as páginas são públicas para compartilhamento de material, permitindo a interação através de comentários e a possibilidade de curtir o conteúdo. Somado a isso, o facebook converte o conteúdo para tablets e celulares ampliando assim o seu alcance (MATTAR, 2012).

Para utilização dessas tecnologias é fundamental que o professor conheça a fundo seu funcionamento, de modo a orientar os alunos na realização das atividades propostas e sempre que possível exemplificar o que pretende realizar.

\subsection{Análise da realidade escolar}

Além da busca por referencial em livros e demais publicação, também se fez necessária uma breve análise da realidade escolar. Nesse sentido, a escola de educação profissional onde foram realizados os estágios está localizada em uma das avenidas de grande movimento, em um prédio com oito salas de aula, sendo que todas possuem quadro branco, ar-condicionado, computador fixo com acesso à internet por cabo, datashow e caixinhas de som. Dessas salas, duas possuem cadeiras com braços e o restante, classes e cadeiras.

Dentro da estrutura de apoio ao docente, destaca-se o setor pedagógico, responsável pelo cronograma de aulas, orientação no preenchimento do diário on-line, reserva de recursos e impressão de material. Importante destacar também a reunião pedagógica que é realizada uma vez por mês com o objetivo de reflexão e troca de experiência entre os professores.

Por fim, é importante também salientar a documentação que envolve o trabalho do docente. Nesse sentido, destaca-se o projeto político e pedagógico da escola (PPP), o projeto pedagógico do curso (PPC) e o planejamento coletivo. Em relação ao PPP, o documento foi 
construído em 2008 com a participação de alunos, pedagogos, professores e setores administrativos, e destaca a importância dos cursos na realização de projetos dos alunos, o perfil do professor da instituição, enfocando a questão da inovação e tecnologia no processo de ensino e aprendizagem, com o objetivo principal de minimizar a distância entre o ambiente acadêmico e o ambiente profissional. Fica clara a presença da corrente construtivista defendida por Paulo Freire.

Além do PPP, o docente também deve conhecer o PPC, que traz a estrutura do curso. $O$ curso Técnico em Administração está dividido em três etapas, sendo que cada uma possui disciplinas específicas. Além disso, o documento traz a carga horária, conhecimento e competências a serem desenvolvidos em cada disciplina, bem como critérios para inscrição no curso e aprovação, tanto em relação a conceito quanto à frequência.

O último documento a ser analisado é o planejamento coletivo. Esse documento, particular da escola, descreve, para cada disciplina prevista, algumas diretrizes de como realizar o trabalho docente. O documento traz informações da disciplina retiradas do PPC, e acrescenta informações de como trabalhar, como avaliar e professores que possam dar suporte.

Com sedimentação das bases da reflexão, partiu-se para a prática docente, que totalizou 64 horas, somadas as cargas horárias da disciplina de Teorias e Fundamentos da Administração e de Gestão da Qualidade. A partir disso são apresentadas as reflexões na sequência deste artigo.

\section{REFLEXÕES: APRESENTAÇÕES PRÁTICAS}

Nesse item são apresentadas as reflexões a partir de situações vivenciadas no exercício da docência, sendo que inicialmente aborda-se a questão do planejamento, seguido por situações específicas de cada uma das disciplinas e finalizando com práticas comuns.

\subsection{Reflexões sobre o planejamento}

No exercício da docência o planejamento é uma etapa importante do processo. Nesse sentido, de acordo com o tipo de didática predominante, muda a forma de se efetuar o planejamento. Em ambas disciplinas, optou-se pela didática tecnicista para fins de planejamento, utilizando-se para tanto o plano de aula como ferramenta. Essa escolha deve-se a necessidade de registro das informações de um plano de aula no diário on-line. Nesse ponto, fica clara a importância do professor adaptar-se as exigências da instituição, que foi o que norteou a escolha da didática. Entretanto, a opção pela didática tecnicista não significa que a forma de trabalho tenha seguido no mesmo rumo, muito pelo contrário, através dos relatos na sequência, verificase uma aproximação das práticas pedagógicas com a didática crítica.

Ainda no que diz respeito ao planejamento, cabe realçar a questão do planejamento do coletivo, descrito na análise da realidade. Para um professor sem experiência de sala de aula, este documento é de grande valia, pois apresenta um caminho a ser seguido, à medida que traz sugestões de como trabalhar determinados conteúdos para que os alunos adquiram as competências previstas. Cabe destacar que este planejamento é uma sugestão para o trabalho do docente, mas que por ser uma compilação de ações que deram certo em oportunidades anteriores, deve ser considerado na elaboração do planejamento do professor. Um bom exemplo 
vem da disciplina de Teorias e Fundamentos da Administração, onde o planejamento coletivo sugere no item como trabalhar, a formação de grupos, para que cada grupo realizasse a leitura e discussão sobre um dos teóricos, para posterior apresentação à turma. No planejamento individual do professor foi mantida essa atividade, acrescentando que a apresentação deveria ser realizada de uma forma atraente e atual, utilizando-se de recursos tecnológicos como redes sociais, vídeos entre outros. A título de inspiração, foi apresentada a história da II Guerra Mundial contada no Facebook através de perfis dos países envolvidos. No item 3.4 é comentado o resultado dessa atividade.

\subsection{Reflexões sobre a disciplina de Teorias e Fundamentos da Administração}

Como prática realizada dentro do Estágio I nesta disciplina, destaca-se a apresentação do professor no primeiro dia de aula, que também foi o primeiro dia de aula daquela turma. 0 professor vestiu-se como aluno: tênis, calça de brim e camiseta e chegando mais cedo, abriu a sala e sentou-se do meio para o fundo da sala escutando música no celular. Os alunos vinham chegando e sentando-se, a maioria também do meio para o fundo. Próximo do início da aula a pedagoga chegou e deu as boas-vindas aos alunos, pedindo que os mesmos se apresentassem, destacando nome, cidade, onde trabalha entre outros dados. A apresentação iniciou-se pelos alunos da frente, sendo que quando chegou à vez do docente, o mesmo apresentou-se com nome, disse que era graduado em administração, técnico em transações imobiliárias, especialista em educação a distância, aluno do curso de formação pedagógica e professor daquela disciplina. No início os alunos estava quietos, muito pelo fato de ser a primeira aula do curso, entretanto quando o até então colega falou da sua formação muitos levantaram a cabeça para ver quem estava falando. Essa forma inusitada teve dois motivos: o primeiro pelo fato do professor ser exaluno da escola no curso técnico e o segundo para mostrar que embora aquela pessoa fosse o professor, estaríamos juntos nesta disciplina e juntos construiríamos o conhecimento e as competências previstas, e que, para isso, era fundamental a participação de todos. Além disso, tentaríamos trabalhar a teoria e fundamentos, que normalmente são vistos como algo chato, de uma forma diferente e surpreendente, assim como foi a apresentação do docente.

\subsection{Reflexões sobre a disciplina de Gestão da Qualidade}

Já no Estágio II, dentro da disciplina de Gestão da Qualidade destaca-se como prática específica o desenvolvimento do projeto Aula de Qualidade sobre Qualidade. O objetivo dessa ação foi refletir sobre o que é e como ter uma aula de qualidade no curso Técnico em Administração da escola. A partir dessa reflexão, a ideia é que os professores possam executar suas atividades atendendo às expectativas e aos anseios dos alunos, e consequentemente garantindo a satisfação dos mesmos. Para realização do projeto fez-se uso de diferentes ferramentas da qualidade entre elas o diagrama de causa e efeito, onde, após a exposição inicial do funcionamento da ferramenta, foi construído um diagrama para identificar as causas de uma aula de qualidade (FIGURA 1). 
Figura 1: Diagrama de causa e efeito

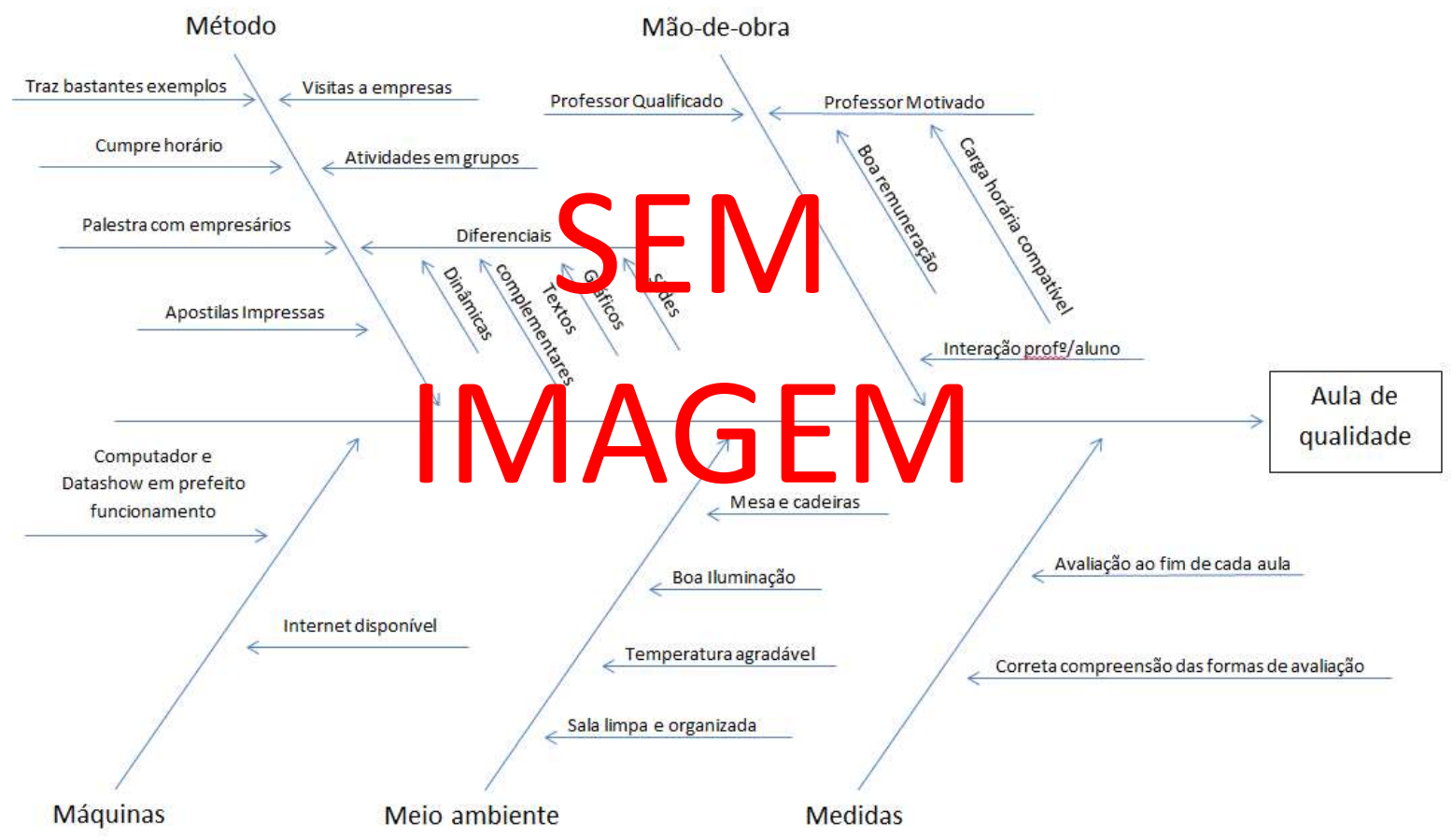

Alguns comentários importantes em relação ao diagrama. A turma em questão estava até a oitava aula, em uma sala com cadeira de braços, e, em função do que foi proposto, conseguiram trocar, passando para uma sala com mesas e cadeiras. A questão de palestras com empresários ocorrem em grande parte das disciplinas, sendo que no caso desta em específico, houve a palestra da presidente do Comitê Regional da Qualidade na última aula. Por fim, cabe destacar a relação entre trazer exemplos com o item professor motivado. Exemplos, dentro da administração, são frutos da vivência profissional, das experiências pelas quais o professor já passou ou está passando. Nesse sentido é fundamental que além da carreira docente, o professor também esteja inserido no mercado, tendo assim uma dupla carreira. Entretanto, essa dupla carreira, pode comprometer a motivação do professor em função da carga horária excessiva, caso não haja equilíbrio.

\subsection{Reflexões gerais}

Neste item são apresentadas ações que ocorreram nas duas disciplinas, bem como seus resultados. A primeira ação ocorreu no início de todas as aulas. Após os cumprimentos iniciais, toda aula era iniciada com uma frase que tivesse relação com o conteúdo trabalhado na sequência. Como exemplos temos a frase de Albert Einstein que diz que "Se quer viver feliz amarre-se a uma meta, não às pessoas nem as coisas" (ALBERT EINSTEIN apud DORNELES, 2011, 
p. 5) utilizada na aula de Teorias e Fundamentos da Administração quando foi trabalhado administração por objetivos. Já em Gestão da Qualidade, destaca-se a frase utilizada quando estudamos fluxograma, "Um bom esquema vale mais do que um longo discurso" (NAPOLEÃO BONAPARTE apud PENSADOR, 2015, texto digital). Além de ser uma forma diferente de introduzir o assunto, a relação frase e assunto também foi alvo de uma questão de prova, onde foi solicitado que os alunos relacionassem uma das frases ditas pelo professor no início de uma das aulas com um dos conteúdos trabalhados, justificando sua resposta. Nessa questão, percebeu-se que um baixo percentual de alunos conseguiu fazer essa relação, destacando que não era necessário colocar a frase completa, apenas a essência dela. Percebeu-se também que o percentual de alunos que acertaram a questão foi maior na disciplina de Gestão da Qualidade, provavelmente por serem alunos que já estavam na metade do curso e por terem conversado com outros alunos, e com isso já conhecendo essa prática. Outro fator que contribuiu para isso, diz respeito ao perfil do aluno de curso técnico, que ainda espera tudo pronto, para apenas decorar para a prova, quando deveria pensar, refletir e questionar sobre o que está aprendendo.

A segunda prática que teve êxito foi a aplicação do Teste Vark para avaliar estilos de aprendizagem predominantes na turma e com base nisso realizar o planejamento. Na tabulação das respostas, em ambas as turmas, teve um predomínio do perfil cinestésico, ou seja, aquelas pessoas que aprendem de uma forma melhor quando fazem; seguido do perfil auditivo, que aprendem ouvindo. Em função disso, procurou-se desenvolver atividades práticas, com destaque para os trabalhos em grupo sobre os teóricos da administração e a atividade de construção do símbolo da administração na disciplina de Teorias e Fundamentos da Administração e a atividade de brainstorming e construção do diagrama de causa e efeito (FIGURA 1), o desenvolvimento do Gráfico de Pareto no Excel, a criação do fluxograma com as etapas do MASP e o trabalho sobre os gurus da qualidade na disciplina de Gestão da Qualidade. As duas turmas acharam importante à realização do teste e compreenderam a importância do resultado na atividade de planejamento das aulas.

Outra questão que merece comentários diz respeito aos trabalhos, tanto sobre os teóricos da administração quanto sobre os gurus da qualidade. No primeiro caso, foi apresentada apenas a história da II Guerra Mundial contada no Facebook através de perfis dos países envolvidos e solicitado que os alunos apresentassem os teóricos de uma forma atual e atraente. Para isso poderiam utilizar diferentes recursos entre eles as redes sociais. Dos sete grupos, apenas três cumpriram a atividade com êxito, com destaque para o perfil de Fayol no Facebook, o perfil de Weber no Instagram, o mapa mental sobre Bertalanffy no Examtime. Os outros grupos se limitaram a apresentação por slides, tendo como destaque negativo o excesso de informação por slide. Já na disciplina de Gestão da Qualidade, foi utilizado como inspiração o perfil de Fayol que o grupo de Teorias e Fundamentos da Administração havia feito, e solicitado que construíssem um perfil no Facebook falando do guru e suas contribuições. Além disso, nesse caso foram solicitadas algumas questões específicas: constar que o perfil foi elaborado para a disciplina de Gestão da Qualidade do curso Técnico em Administração da escola; foto e nomes dos integrantes; fonte das informações postadas; e plano de ação das etapas para realização do trabalho. Dos sete gurus a serem apresentados, apenas um atendeu a todas as exigências. Um dos grupos não fez o perfil, outro fez, mas apenas colocando as informações do conteúdo, sem organizar e sem cumprir os outros requisitos. O último grupo não conseguiu apresentar o trabalho com o perfil no Facebook, pois se tratava de uma pessoa ainda viva, sendo que sempre que o grupo criava o perfil o site excluía na sequência por acreditar tratar-se de perfil falso. Esse grupo apresentou como plano B uma apresentação em slides. Na disciplina de Gestão da 
Qualidade, percebeu-se uma falta de comprometimento dos alunos para a realização dos trabalhos, principalmente no que diz respeito à pesquisa. Já de uma forma geral, percebe-se que os alunos ainda não descobriram a possibilidade de usar as redes sociais como ferramenta de aprendizagem mais interessante e atraente do que uma simples apresentação de slides.

Além do que já foi apresentado, cabe destacar uma prática realizada na maioria das aulas ao fim da noite. Sabendo que os alunos em sua maioria trabalham durante o dia e estudam durante a noite, normalmente as aulas eram finalizadas com uma mensagem que trouxesse algo que os estudantes pudessem levar de lição ou reflexão para suas vidas. Essa prática foi adotada, pois, muitas vezes, os alunos acabam vindo para aula cansados e não conseguem ter um aproveitamento eficaz, sendo que, com a mensagem, a ideia era de que levassem algo para suas vidas daquelas três horas que passaram na escola. Dentro das mensagens, foram utilizados textos, vídeos, músicas e dinâmicas. Com isso, além de auxiliar na construção do saber acadêmico, também se auxilia na construção de melhores cidadãos.

Por fim, na última aula de cada disciplina o professor teve por prática a entrega de uma lembrança aos alunos com uma frase e imagem de um ponto turístico da cidade. A frase foi escolhida por inspirar a atuação do docente enquanto professor, e a imagem, por ser um lugar interessante em meio à natureza para recuperar as energias e realizar um passeio de fim de semana (FIGURA 2).

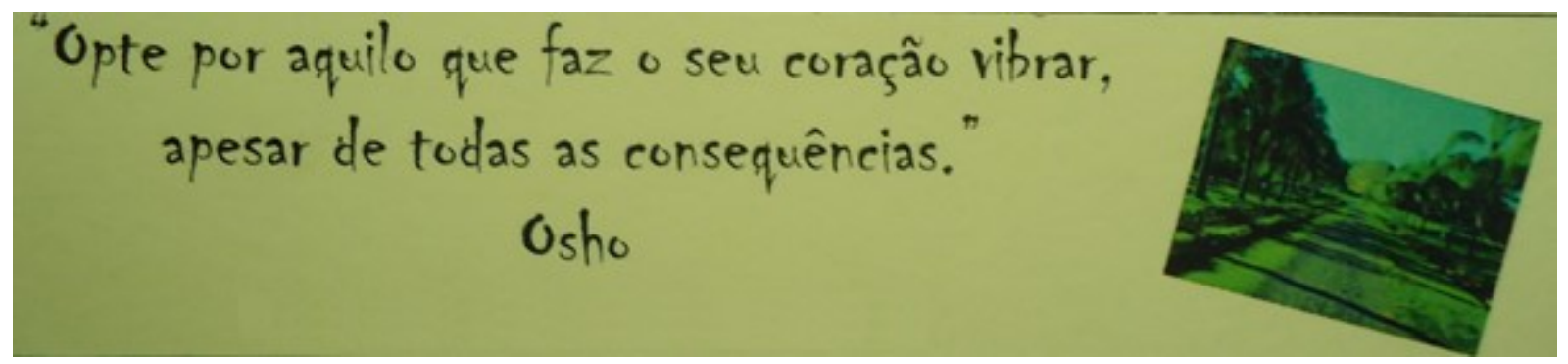

Figura 2: Lembrança para os alunos

Todas essas práticas visaram uma aula de qualidade e que fosse ao mesmo tempo diferente e interessante para os alunos. Nesse sentido, destaca-se o e-mail recebido de um aluno, que despontou como uma das lideranças da turma de Teorias e Fundamentos da Administração: "Bom dia professor! Em nome de toda turma agradecemos por tudo, foi muito bom ter um professor assim como você! Obrigada! Abraços.".

\section{CONSIDERAÇÕES FINAIS}

O presente artigo apresentou de forma sucinta ações desenvolvidas durante a parte prática da construção do professor, ou seja, dos Estágios I e Il do Programa Especial de Formação Pedagógica. Entretanto, cabe destacar que, para realização da prática, foi necessário o estudo da teoria pedagógica, sendo que, uma pequena parte, foi apresentada no referencial teórico. Ao relacionar teoria e prática, tem-se uma frase clássica de Paulo Freire que diz: "A teoria sem a prática vira 'verbalismo', assim como a prática sem teoria vira ativismo. No entanto quando se une a prática com a teoria tem-se a práxis, a ação criadora e modificadora da realidade" (FREIRE, 1996, p. 25). 
Nesse sentido, retoma-se o contexto apresentado na introdução, de constantes mudanças. Entre as mudanças em curso, destaca-se a da atividade docente. O professor deixou de ser dono da informação para atuar como um mediador em um processo de construção do conhecimento, sendo que para isso deve estar atento a novas tecnologias que possam tornar suas aulas mais interessantes. A partir disso, buscou-se colocar em prática essa questão, desde a apresentação do professor até o uso de redes sociais passando pela utilização das ferramentas da qualidade em sala de aula, conforme já apresentado. Entretanto ao longo dos dois estágios, percebeu-se que a maioria dos alunos ainda enxergam o professor como um transmissor do conhecimento e não como um mediador. A causa pode estar no ensino básico, onde essa é a postura de parte dos docentes. Além disso, destaca-se a questão das redes sociais, que apesar de fazerem parte do dia a dia dos alunos, ainda não fazem parte das estratégias de aprendizagem dos mesmos. Fato esse comprovando com os trabalhos sobre teóricos da administração e gurus da qualidade. Somado a isso, existe uma cultura do copiar e colar, sem a preocupação de compreender o que está sendo exposto. Fato este, identificado nos trabalhos e também na compreensão e relação da frase inicial de cada aula com o conteúdo trabalhado. Em função disso, fica clara a importância do professor, que deve ser um dos agentes de mudança, seja estimulando os alunos a terem um pensamento crítico seja descobrindo potenciais de novas tecnologias para a aprendizagem. Nesse sentido destaca-se a necessidade da reconstrução dos profissionais como professores.

Entretanto, essa reconstrução nem sempre é fácil, pois acaba mexendo na situação de equilíbrio, obrigando as pessoas a saírem da sua zona de conforto além de demandar tempo, o que o professor dificilmente tem a sua disposição. A reconstrução passa pela reflexão da atuação como docente, que envolve a pesquisa, o planejamento, a execução e a avaliação, sendo este ciclo retomando constantemente. Nesse ponto destaca-se a construção desse trabalho que, seguindo ciclo de reflexão culminou na elaboração deste artigo, que pode servir de inspiração para a (re)construção dos docentes da educação profissional.

\section{REFERÊNCIAS}

1. BRASIL. Lei 9.394, de 20 de dezembro de 1996. Lei de Diretrizes e Bases da Educação. Disponível em: <http://www.planalto.gov.br/ccivil_03/leis/l9394.htm>. Acesso em 20 jun. 2015.

2. CORALINA, Cora. Vintém de cobre: meias confissões de Aninha. Goiânia: UFG Editora, 1983.

3. DORNELES, Fabiana Winovski. Aprendizagem de ontologias para o apoio ao processo de desenvolvimento de software orientado a conhecimento. 2011. 139 f. Dissertação (Mestrado) - Programa de Pós Graduação em Ciência da Computação, Pontifícia Universidade Católica, Porto Alegre, 24 mar. 2011. Disponível em: <http://tede.pucrs.br/tde_busca/arquivo.php?codArquivo=3626>. Acesso em: 27 jun. 2015.

4. FREIRE, Paulo. Pedagogia da autonomia: Saberes necessários à prática educativa. São Paulo: Editora Paz e Terra, 1996.

5. GANDIN, Daniel. O planejamento como ferramenta de transformação da prática educativa. Disponível

em: 
<www.maxima.art.br/arq_palestras/planejamento_como_ferramenta_(completo).doc>. Acesso em: 03 out. 2014.

6. KENSKI, Vani Moreira. Tecnologias e ensino presencial e a distância. 9. ed. Campinas: Papirus, 2012.

7. MASETO, Marcos Tarciso. Didática: a aula como centro. 4. ed. São Paulo: FTD, 1997.

8. MATOS, Sonia Regina da Luz. Didática das forças vertiginosas. IN: CONJUNTURA. V. 14, n. 1, jan/maio de 2009.

9. MATTAR, João. Games em educação: como os nativos digitais aprendem. São Paulo: Pearson Pretince Hall, 2010.

10. Tutoria e interação em educação a distância. São Paulo: Cengage Learning, 2012.

11. MINISTÉRIO DA EDUCAÇÃO. Resolução № 6, de 20 de setembro de 2012. 2012. Disponível em:

<http://portal.mec.gov.br/index.php?option=com_docman\&task=doc_download\&gid=11663 \&ltemid=>. Acesso em: 27 jun. 2015.

12. MINISTÉRIO DA EDUCAÇÃO. O que é o Pronatec? 2015. Disponível em: <http://pronatec.mec.gov.br/institucional-90037/o-que-e-o-pronatec>. Acesso em: 20 jun. 2015.

13. NÍVEIS Educação Profissional. SINPRO/RS. Porto Alegre. 12 jul. 2008. Disponível em $<$ http://www.sinpro-

rs.org.br/noticias.asp?id_noticia=578\&key_noticia=5a58KDRG84jVa9GIr5TJ>. Acesso em: 20 jun. 2015.

14. PENSADOR. 2015. Disponível em <http://pensador.uol.com.br/frase/MTUONTQ/>. Acesso em: 20 jun. 2015.

15. SENAC DN. Planejamento e avaliação: subsídios para a ação docente. 4. ed. Rio de Janeiro: Senac Nacional, 2009. 